\title{
Intervertebral Disc Characteristic on Progressive Neurological Deficit
}

\author{
Farid Yudoyono, Rully Hanafi Dahlan, Muhammad Zafrullah Arifin \\ Department of Neurosurgery, Faculty of Medicine, Universitas Padjadjaran-Dr. Hasan Sadikin General Hospital, \\ Bandung
} \begin{abstract}
$\begin{array}{ll}\text { Abstract } & \text { Objective: To examine the intervertebral disc characteristic on magnetic } \\ \text { resonance imaging (MRI) in lumbar herniated disc (LHD) patients with }\end{array}$ progressive neurological deficit.

Methods: Patients were collected retrospectively from Dr. Hasan Sadikin General Hospital Database from 2011-2013 with LHD, had neurological deficit such as radiculopathy and cauda equine syndrome for less than four weeks with a positive sign confirmed by neurological examination and confirmatory with MRI examination.

Results: A total of 14 patients with lumbar herniated disc disease (10 males, 4 females) suffered from progressive neurological deficit with an average age of $(52.07 \pm 10.9)$ years old. Early disc height was $9.38 \pm 0.5 \mathrm{~mm}$ and progressive neurological deficit state disc height was $4.03 \pm 0.53 \mathrm{~mm}$, which were significantly different statisticaly $(p<0.01)$. Symptoms of radiculopathy were seen in 11 patients and cauda equine syndrome in three patients. Modic changes grade 1 was found in five patients, grade 2 in eight patients,grade 3 in one patient, Pfirmman grade 2 in eleven patients and grade 3 in three patients. Thecal sac compression $1 / 3$ compression was seen in four patients and $2 / 3$ compression in ten patients.
\end{abstract}

Received:

May 5, 2017

Conclusions: Neurosurgeon should raise concerns on the characteristic

Revised:

July 31, 2017 avoid further neural injury in lumbar herniated disc patients.

Accepted:

August 28, 2017

Keywords: Lumbar herniated disc, magnetic resonance imaging, progressive neurological deficit

pISSN: 2302-1381; eISSN: 2338-4506; http://doi.org/10.15850/ijihs.v5n2.1042

IJIHS. 2017;5(2):70-4

\section{Introduction}

Significant impacts of the implementation of the National Health Insurance scheme were seen in the annual increase of the incidence of low back pain (LBP) with a considerable loss of working time and socioeconomic burden. Increased older age population and changes in the intervertebral disc characteristics that are associated with repetitive minor trauma at endplate can cause low back pain (LBP). Although imaging studies showed that disc degeneration strongly correlate with LBP, not all of disc degeneration are symptomatic. ${ }^{1-7}$

\section{Correspondence:}

Farid Yudoyono, Department of Neurosurgery, Faculty of Medicine, Universitas Padjadjaran-Dr. Hasan Sadikin General Hospital

Jl. Pasteur No. 38, Bandung, Indonesia

e-mail: faridspine@gmail.com
Intervertebral disc is a structure that has a viscoelastic and avascular nature which makes it possible for the degeneration process to change the anatomy of the disc. Early phase noticeable by proteoglycan depletion and reduce of water content, changes osmotic pressure. Therefore, early diagnosis of disc degeneration is critical for the success of any modality of treatment strategy., ${ }^{8,9}$

The etiologic factors of nocioceptive and disability caused by pathological disc is still currently debatable.,10 A common belief is that changes the diffusion of water will result in structural changes in nucleus pulposus, annulus and end plate that are altered the internal disc stability. ${ }^{11,12}$ Magnetic resonance imaging (MRI) is highly accurate in detecting abnormality of the disc, but the relationship between findings on MRI and clinical course 
remains controversial..$^{5,6,13,14}$

\section{Methods}

Ethical approval for the current study was granted by the Ethics Committee of the Faculty of Medicine, Universitas Padjadjaran. The patients were collected retrospectively from Dr. Hasan Sadikin General Hospital Database for the period of 2011-2013 by including those with a diagnosis of LHD, a history of radiculopathy and cauda equine syndrome with progressive neurological deficit within less than four weeks with concomitant neurologic examination that correlated with the same nerve root being affected and a confirmatory cross-sectional imaging study demonstrating a herniated disc at the level and side corresponding to their symptoms. The exclusion criteria comprised of malignancy, significant deformity, prior back surgery and other established contraindications to elective surgery.

Lumbar spine MRI were acquired using magnets operating at field strength of 1.5 Tesla with axial and sagittal T1 weighted, T2 weighted. Images were collected as printed films and then digitized using computer system. All images were identified for patient confidentiality. Patients received either a standard open discectomy or decompression of the involved nerve. Disc Height was defined as the disc height measured as the distance between the inferior endplate to the superior endplate at middle vertebral body line performed by MRI and plain lumbal radiograph for repeated examinations. ${ }^{15,16}$ The assessment included the followings: disc morphology, thecal sac modified compression by the disc fragment characterized as non, $<1 / 3,2 / 3$, or $>2 / 3$ as a relative term for canal compromise secondary to disk herniation; disc degeneration described by Pfirrmann; endplate marrow abnormality according to the Modic classification in which Modic 1 refers to edema-like signal intensity, Modic 2 refers to fat-like signal intensity and Modic 3 refers to sclerosis-like signal intensity (Fig. 1 and 2). 5,17-20

Data analyses were performed using SPSS version 13 for Windows (SPSS, Inc, Chicago, IL, USA). Data are presented as the number of subjects in each group or mean \pm SD. Each independent variable was compared using the t test.

Table 1 Patients Characteristics

\begin{tabular}{cccccccccc}
\hline Sex & Age & Level & Symptoms & $\begin{array}{c}\text { DH } \\
\text { early } \\
\mathbf{m m} \text { ) }\end{array}$ & $\begin{array}{c}\text { DH } \\
\text { prog } \\
\mathbf{( m m )}\end{array}$ & $\begin{array}{c}\text { Bulging } \\
\text { Type }\end{array}$ & Modic & Pfirmman & $\begin{array}{c}\text { Thecal } \\
\text { Sac }\end{array}$ \\
\hline M & 64 & L345 & Rad. & 10 & 5.3 & protruded & 1 & 3 & $2 / 3$ \\
M & 67 & L345 & Rad. & 9 & 4.3 & protruded & 1 & 3 & $2 / 3$ \\
F & 32 & L5S1 & Rad. & 10 & 5.7 & protruded & 1 & 3 & $1 / 3$ \\
F & 33 & L5S1 & Rad. & 9.5 & 4.4 & prostruded & 1 & 3 & $1 / 3$ \\
F & 50 & L5S1 & CES & 9.2 & 3.7 & protruded & 1 & 3 & $2 / 3$ \\
M & 62 & L345 & Rad. & 10.3 & 3.4 & extruded & 2 & 3 & $2 / 3$ \\
M & 62 & L345 & Rad. & 9.2 & 3.2 & extruded & 2 & 3 & $2 / 3$ \\
F & 45 & L45S1 & CES & 9 & 4.7 & protruded & 2 & 2 & $2 / 3$ \\
M & 45 & L45S1 & Rad. & 8.9 & 4.5 & extruded & 2 & 2 & $1 / 3$ \\
M & 56 & L45 & Rad. & 9 & 3.3 & extruded & 3 & 3 & $2 / 3$ \\
M & 58 & L45 & Rad. & 10.3 & 4.8 & protruded & 2 & 2 & $2 / 3$ \\
M & 59 & L345 & CES & 9.2 & 3.2 & extruded & 2 & 3 & $2 / 3$ \\
M & 47 & L345 & Rad. & 8.8 & 3.1 & extruded & 2 & 3 & $2 / 3$ \\
M & 49 & L23 & Rad. & 9 & 2.9 & extruded & 2 & 3 & $2 / 3$ \\
\hline
\end{tabular}

Notes: $\mathrm{DH}=$ disc height, $\mathrm{F}=$ female, $\mathrm{M}=$ male, $\mathrm{L}=$ lumbar; Early= first radiological examination, Prog= pregressive neurological deficit tim, Rad.= radiculopathy, $\mathrm{CES}=$ cauda equina syndrome 
Table 2 Study Results

\begin{tabular}{|c|c|}
\hline Variables & Value \\
\hline Patients & 14 \\
\hline Sex & $\mathrm{F}=4 / \mathrm{M}=10$ \\
\hline Age (years old) & $52.07 \pm 10.9$ \\
\hline \multicolumn{2}{|l|}{ Level } \\
\hline L23 & 1 \\
\hline L345 & 6 \\
\hline L45 & 2 \\
\hline L45S1 & 2 \\
\hline L5S1 & 3 \\
\hline \multicolumn{2}{|l|}{ Symptom } \\
\hline Radiculopathy & 11 \\
\hline Cauda equina synd & 3 \\
\hline DH early (mm) & $9.38 \pm 0.5$ \\
\hline DH progressive $(\mathrm{mm})$ & $4.03 \pm 0.53$ \\
\hline \multicolumn{2}{|l|}{ Bulging type } \\
\hline Protruded & 7 \\
\hline Extruded & 7 \\
\hline \multicolumn{2}{|l|}{ Modic } \\
\hline Grade 1 & 5 \\
\hline Grade 2 & 8 \\
\hline Grade 3 & 1 \\
\hline \multicolumn{2}{|l|}{ Pfirmman } \\
\hline Grade 1 & 0 \\
\hline Grade 2 & 11 \\
\hline Grade 3 & 3 \\
\hline \multicolumn{2}{|l|}{ Thecal sac compression } \\
\hline Normal & 0 \\
\hline $1 / 3$ & 3 \\
\hline $2 / 3$ & 11 \\
\hline
\end{tabular}

\section{Results}

A total 14 patients with lumbar herniated disc disease (10 males, 4 females) suffering from progressive neurological deficit with avarage age of $(52.07 \pm 10.9)$ years old between January 2012 and December 2013 were evaluated retrospectively. Early disc height of $9.38 \pm 0.5$ $\mathrm{mm}$ and progressive disc height of $4.03 \pm 0.53$ $\mathrm{mm}$ were found, which were significantly different $(p<0.01)$. One, six, two, two and three patients had LHD at the L2-3,L3-4-5,L4-5,L45-S1,L5-S1 levels. Symptoms of radiculopathy were found in 11 patients and cauda equine syndrome in three patients. Protruded disc was seen in 7 patients and extruded type in 7 patients. Modic changes grade 1 was revealed in five patients, grade 2 in eight patients and grade 3 in one patient. Pfirmman grade 2 was found in eleven patients and grade 3 in three patients. Thecal sac compression $1 / 3$ compression was observed in three patients and $2 / 3$ compression in eleven patients.

\section{Discussion}

With the increasing size of aging population, a higher prevalence of clinical disability related to disc degeneration disease is seen. Lumbar herniated disc was the most common cause of low back pain and it was observed as a major aspect of disc degeneration around the globe. Advances in the development of neuroimaging technology allows an excellent noninvasive means of imaging for the entire lumbar spine. The contrast, sensitivity and also the multi planer images help clarifying the disc anatomy within or adjacent spine. Intervertebral disc characteristic of the lumbar spine has been play important role in development of low back pain. Recent studies have reported the usefulness of routine use of MRI in evaluating of nerve root compression and relation with clinical symptoms. ${ }^{17}$

By gender, men were more prone to LDH, which is a warning for society. The findings of our study are consistent with those of other studies. ${ }^{5}$ This results showed that men are more susceptible to disc degeneration when compared to women, which is most likely due to increased mechanical stress and injury.

In this study, the authors found the disc height reduced significantly before the surgery. This supports the hypothesis of the previous study. ${ }^{6}$ The previous study showed that more than $50 \%$ decrease disc height in painfull degenerative disc. A previous study found that a Modic change includes segmental instability and strongly correlation with progression of neurological symptoms. ${ }^{18}$ However, another previous studies showed that Modic changes in the degenerative process of disc in relation to back pain and associated with aggravation of neurological deficit. ${ }^{19}$ In this study, the authors found that grade 2 of modic changes were found in $57 \%$ of subjects, meaning a high number of increased modic changes as reactive bone and granulation tissue are found 


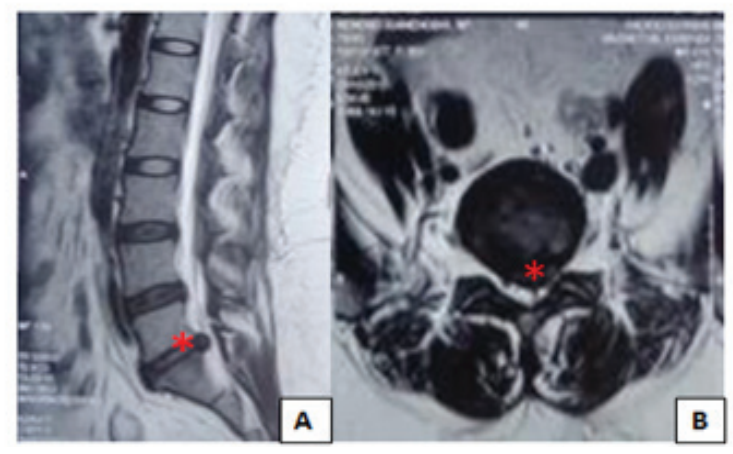

Fig. 1 Lumbar Herniated Disc on Sagittal T2 Weighted Image, A) Axial T2 Weighted Image (red asterixs)

in early phase of degenerative process. ${ }^{20}$

A previous study has reported Pfirmann grading use in assessing disc degeneration on MRI, and it associated with increasing back pain. ${ }^{19}$ Current findings of this study could support the extension of this hypothesis since the majority of participants had disc degeneration of Pffirman grade 2, i.e. w11 patients $(78 \%)$, which is similar to the results of the study by Hansen et al. ${ }^{19}$ A previous study by Albert et al. ${ }^{20}$ reported that MRI change findings in the lumbar intervertebral disc have a significant association with age, indicating LBP. The study shows that the average age of lumbar herniated disc patients is more than 50 years old, i.e. $52.07 \pm 10.9$ years old. People of that age seems to be vulnerable because of the decrease in the elasticity and water content of the nucleus with age. 3,15

Our current study found that lumbar level 345 was observed in six patients (43\%). This is due to the fact that lumbar spine carries most of the body weight. Thecal sac compression or canal was found to be $2 / 3$ compromised in 11 patients $(71 \%)$, which is similar to what was revealed in the study by Lurie et

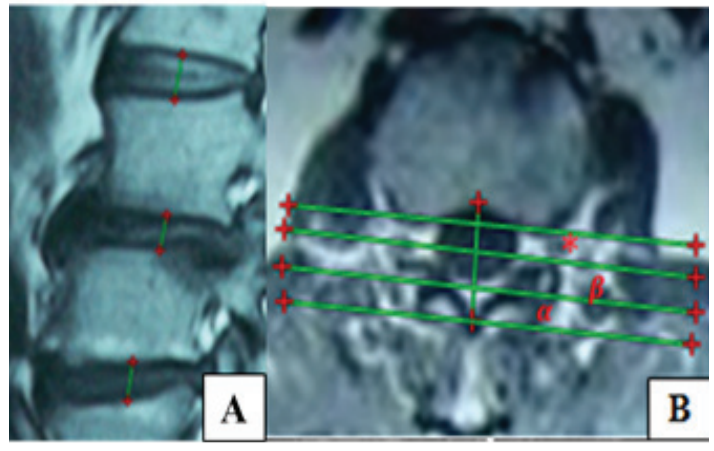

Fig. 2 Disc Height Measurement and Modic Changes B) Thecal sac Compression Measurement $1 / 3$ (asterix), 2/3 ( $\beta$ ) and $>2 / 3(\alpha)$

$a l^{5}$ These consistent findings suggest that compromised canal may denote as the guide point of neurological deficit that is related to LHD perioperatively.

In lumbar degenerative disc patients, the intervertebral disc has a wide range of presentations including changes in disc height, endplate, and within the disc, simoultaneously. In contrast, the current study shows that changes in the intervertebral disc morphology relates to progressive neurological deficit.

There are several limitations to our study. Although MRI has become the gold standard for imaging of LDH due to its ability to capture vertebral bone and soft tissue pathology, it is quite expensive that the use is limited due to funding considerations. Furthermore, the small sample size in this study may make the estimates for these subgroups imprecise. Therefore, further studies specifically designed to evaluate these future are needed $t$.

In conclusion, neurosurgeon should raise concerns on the characteristic changes of intervertebral disc in magnetic resonance imaging examination to avoid further neural injury in lumbar herniated disc patients.

\section{References}

1. Le Maitre CL, Freemont AJ, Hoyland JA. Accelerated cellular senescence in degenerate intervertebral discs: a possible role in the pathogenesis of intervertebral disc degeneration. Arthritis Res Ther. 2007;9(3):112.

2. Peng B, Fu X, Pang X, Li D, Liu W, Gao C, Yang H. Prospective clinical study on natural history of discogenic low back pain at 4 years of followup. Pain Physician. 2012;15(6):525-32.

3. Kato F, Yukawa Y, Suda K, Yamagata M, Ueta T. Normal morphology, age-related changes and 
abnormal findings of the cervical spine. Part II: magnetic resonance imaging of over 1,200 asymptomatic subjects. Eur Spine J. 2012; 21(8):1499-507.

4. el Barzouhi A, Vleggeert-Lankamp CL, Lycklama à Nijeholt GJ, Van der Kallen BF, van den Hout $\mathrm{WB}$, Jacobs WC, et al. Magnetic resonance imaging in follow-up assessment of sciatica. $\mathrm{N}$ Engl J Med. 2013;368(11):999-1007.

5. Lurie JD, Moses RA, Tosteson ANA, Tosteson TD, Carragee EJ, Carrino JA, et al. Magnetic resonance imaging predictors of surgical outcome in patients with lumbar intervertebral disc herniation. Spine (Phila Pa 1976). 2013;38(14):1216-25.

6. O'neill C, Kurgansky M, Kaiser J, Lau W. Accuracy of MRI for diagnosis of discogenic pain. Pain Physician. 2008;11(3):311-26.

7. Boyd LM, Richardson WJ, Allen KD, Flahiff C, Jing L, Li Y, et al. Early-onset degeneration of the intervertebral disc and vertebral end plate in mice deficient in type ix collagen. Arthritis Rheumatism. 2008;58(1):164-71.

8. Cortes DH, Magland JF, Wright AC, Elliott DM. The shear modulus of the nucleus pulposus measured using mr elastography: a potential biomarker for intervertebral disc degeneration. Magn Reson Med. 2014;72(1): 211-9.

9. Melrose J, Smith SM, Appleyard RC, Little CB. Aggrecan, versican and type vi collagen are components of annular translamellar crossbridges in the intervertebral disc. Eur Spine J. 2008;17(2):314-24.

10. Schenk P, Läubli T, Hodler J, Klipstein A. Magnetic resonance imaging of the lumbar spine: findings in female subjects from administrative and nursing professions. Spine (Phila Pa 1976). 2006;31(23):2701-6.

11. Beattie PF, Morgan PS, Peters PD. Diffusionweighted magnetic resonance imaging of normal and degenerative lumbar intervertebral discs: a new method to potentially quantify the physiologic effect of physical therapy intervention. J Orthop Sports Phys Ther. 2008;38(2):42-9.

12. Abu-Ghanem S, Ohan N, Abu-Ghanem Y, Kitta M, Shelef I. Acute schmorl node in dorsal spine: an unusual cause of a sudden onset of severe back pain in a young female. Asian Spine J. 2013;7(2):131-5.

13. Takashima $H$, Takebayashi $T$, Yoshimoto $M$, Terashima Y, Tsuda $\mathrm{H}$, Ida $\mathrm{K}$, Yamashita $\mathrm{T}$. Correlation between $\mathrm{t} 2$ relaxation time and intervertebral disk degeneration. Skeletal Radiol. 2012;41(2):163-7.

14. Sa N, Juhasz I, Komaromy $H$, Pozsar $K$, Zsigmond I, Perlaki G, et al. A statistical model for intervertebral disc degeneration: determination of the optimal t2 cut-off values. Clin Neuroradiol. 2014;24(4):355-63.

15. Ma DY, Liang Y, Wang D, Liu Z, Zhang W, Ma $\mathrm{T}$, et al. Trend of the incidence of lumbar disc herniation: decreasing with aging in the elderly. Clin Interv Aging. 2013;8:1047-50.

16. Phan K, Mobbs RJ,. Rao PJ. Foraminal height measurement techniques. J Spine Surg. 2015;1(1):35-43.

17. Hilal K, Sajjad Z, Sayani R, Khan D. Utility of limited protocol magnetic resonance imaging lumbar spine for nerve root compression in a developing country, is it accurate and cost effective? Asian Spine J. 2013;7(3):184-9.

18. Zhang $\mathrm{YH}$, Zhao CQ Jiang LS, Chen XD, Dai LY. Modic changes: a systematic review of he literature. Eur Spine J. 2008;17(10):1289-99.

19. Hansen BB, Bendix T, Grindsted J, Bliddal $\mathrm{H}$, Christensen $\mathrm{R}$, Hansen $\mathrm{P}$, et al. Effect of lumbar disc degeneration and low-back pain on the lumbar lordosis in supine and standing: a cross-sectional MRI study. SPINE. 2015;40(21):1690-6.

20. Albert HB, Kjaer P, Jensen TS, Sorensen JS, Bendix T, Manniche C. Modic changes, possible causes and relation to low back pain. Medical Hypotheses. 2008;70(2):361-8. 